\title{
Glass Transition Measurements of Ultrathin Polystyrene Films
}

\author{
Cynthia Buenviaje, Franco Dinelli, René M. Overney \\ Department of Chemical Engineering, \\ University of Washington, Seattle WA 98195
}

\begin{abstract}
Data from various experiments suggest that the mechanical properties of thin polymer films depend, in a complex manner, on the film preparation process, in conjunction with interfacial interactions. In this paper, we discuss how and why interfacial interactions can affect the shear mechanical properties of spincoated polymer films. For example, confinement effects due to the spin coating process have been observed to exceed the nearest neighbor interaction distances by one order of magnitude. We introduce shear modulation scanning probe microscopy (SPM) as a technique to measure local shear property changes in thin polymer films as a function of temperature. Comparisons with bulk and lateral force measurements demonstrate the reliability of the technique. Using the shear modulation SPM, we observe a molecular weight dependence on the bulk glass transition. Measurements taken on polystyrene surfaces of various film thickness provide insight into how the glass transition of films are affected by substrate confinement.
\end{abstract}

Submitted for publication in in "Interfacial Properties on the Submicron Scale" (J. Frommer and R.M. Overney, editors.) American Chemical Society (ACS) Books, 2000 


\section{Introduction}

Although bulk properties of polymers have been studied extensively, many properties of thin films, specifically the glass transition temperature, $T_{g}$, are not as well understood. The $T_{g}$ of amorphous polymers is an important parameter in determining if a polymer can be used in a particular application. Below $\mathrm{T}_{\mathrm{g}}$, an amorphous polymer takes on the characteristics of a glass becoming hard, stiff, and brittle. Above $\mathrm{T}_{\mathrm{g}}$, extensive molecular motions soften the polymer, which then behaves like rubber. For bulk polymers, $\mathrm{T}_{\mathrm{g}}$ is primarily measured either by differential thermal analysis (DTA) or differential scanning calorimetry (DSC). However, for thin films, the amount of polymer in the film is insufficient to obtain reliable results. In recent years, the $\mathrm{T}_{\mathrm{g}}$ of thin polymer films, ranging in thickness from several to thousands of nanometers, has been successfully studied using a variety of experimental techniques. A collection of these techniques is listed in Table 1 along with the phenomena measured.

Table 1. Ultrathin Polymer Glass Transition Temperature Techniques

\begin{tabular}{|c|c|}
\hline Volume Expansion & \\
\hline Ellipsometry & $(1-3)$ \\
\hline X-Ray Reflectivity & $(4,5)$ \\
\hline Positron Annihilation Lifetime Spectroscopy & $(6,7)$ \\
\hline Brillouin Light Scattering & $(8,9)$ \\
\hline Optical Reflectance & (10) \\
\hline Acoustic Wave Spectroscopy & (11) \\
\hline Segmental Mobility & \\
\hline Probe Diffusion & $(12,13)$ \\
\hline Excimer Recombination & (14) \\
\hline Viscoelasticity & \\
\hline Scanning Force Microscopy & $(15-20)$ \\
\hline
\end{tabular}

Experimental results obtained with the techniques, listed in table 1, on similar systems (such as polystyrene with comparable molecular weights) have been found to be inconsistent. Although there is agreement that near the substrate interface, the value of $T_{\mathrm{g}}$ is shifted from the bulk due to confinement and size effects, there is evident contradiction in the direction of the shift. Problems such as local density variations normal to the interface, interfacial roughness, and film imperfections due to partial dewetting are listed as potential causes for these contradicting interpretations (21).

To minimize effects of film inhomogeneities, we proposed local scale measurements. The tool of choice is scanning probe microscopy (SPM) by virtue of its high spatial resolution. A variety of SPM approaches are available in order to probe the temperature dependence and a list of these modes include: 
Phase Lag Method. The phase lag between a small sinusoidal perturbation (applied normally to the sample surface) and the cantilever response is recorded. $\mathrm{T}_{\mathrm{g}}$ is determined as the onset of change in the phase lag (15-17).

Stiffness Method. The stiffness of the polymer surface is determined by force vs. displacement curves. Very stiff cantilevers are used, and $T_{g}$ is defined as the temperature where a change occurs in the slope of the force-displacement curve (18, 19).

Lateral Force Rate Method. The sample is scanned at low load and the lateral force is measured as function of the scan rate at a fixed temperature. Below $\mathrm{T}_{\mathrm{g}}$ the lateral force is expected to be independent of the scan velocity. $T_{g}$ is defined as the temperature at which the onset of rate dependence is observed $(16,17,20)$.

Lateral Force Method. Lateral forces are obtained at low scan velocity while the temperature is increased. $\mathrm{T}_{\mathrm{g}}$ is determined as the increase in the lateral force or friction coefficient (19).

In several SPM studies, a $T_{g}$ higher than the bulk value was observed, even for very thick bulk-like films. It has been suggested that the pressure the tip exerts on the surface could be interpreted as a hydrostatic pressure (22). At a macroscopic level, it is well known that $\mathrm{T}_{\mathrm{g}}$ linearly increases with increasing hydrostatic pressure (0.3 K/MPa for polystyrene) (23). This is interpreted as the effect of subduing the thermal expansion of the material, therefore limiting the formation of free-volume necessary for the glass transition to take place.

In this paper, we will address the complex issue of the mechanical determination of $T_{g}$ at surfaces of thick bulk-like, as well as interfacially confined ultrathin polymer films. First, we will show that the pressure exerted by the tip does not affect the glass transition. Then, we will introduce a novel contact mechanical technique to determine the $T_{g}$ of thin films, shear modulation SPM. Finally we will present $T_{g}$ results on films where interfacial interactions, remaining stress and conformational changes, formed during film preparation, alter the bulk $\mathrm{T}_{\mathrm{g}}$.

\section{Experimental}

Monodispersed polystyrene (PS) ( $\mathrm{M}_{\mathrm{w}} 3 \mathrm{k}$ to $6.5 \mathrm{M} \mathrm{M}_{\mathrm{w}} / \mathrm{M}_{\mathrm{n}}<1.1$ ) (Aldrich Chemical Company Inc. and Polymer Source, Inc) was spin cast on to silicon (100) wafers from toluene solution. The solution concentration was varied to achieve thicknesses ranging from 20 to $350 \mathrm{~nm}$, as determined by ellipsometry (Rudolph, AutoEL). The wafers were hydrogen passivated via HF etching prior to spin casting, and samples were annealed under vacuum $(<400 \mathrm{mtorr})$ for 4 hours at 165 to $170{ }^{\circ} \mathrm{C}$ prior to SPM experiments.

SPM measurements were conducted with a commercial instrument (Explorer, Thermomicroscopes, Inc.) which was mounted onto a modified heating/cooling stage (Model R2700-2, MMR Technologies). The stage, manufactured by MMR Technologies, utilizes the Joule-Thompson effect to cool by gas expansion. Unlike thermoelectric heaters, this stage is very stable over a wide range of temperatures 
( 230 to $425 \mathrm{~K}$ ). Investigations were carried out in a nitrogen flooded dry box to avoid strong capillary forces between the tip and sample. The humidity was maintained around $5 \%$. Bar-shaped cantilevers were employed, with normal spring constants ranging from 0.1 to $0.8 \mathrm{~N} / \mathrm{m}$.

Conventionally, the lateral force is obtained by taking the difference of the average lateral force acting on the tip when scanning along two opposite directions (divided by 2) (24). The tip was moved in the $y$ direction at the end of each line in order not to scan the same region twice. The scan length was $5 \mu \mathrm{m}$ at a speed of 5 $\mu \mathrm{m} / \mathrm{s}$. The results presented were obtained with positive loads only. (It was not possible with the lateral force SPM method to perform $T_{g}$ measurements at negative applied load.) The sample temperature in the lateral force studies was adjusted in increments of 2 to $3 \mathrm{~K}$, and a waiting time of approximately ten minutes was considered sufficient to stabilize the sample temperature.

In figure 1, a schematic of the operative principle for the shear modulation SPM is shown. A sinusoidal signal is applied to the $\mathrm{x}$-piezo inducing an oscillatory local perturbation of the sample surface. The amplitude is chosen below the stick slip threshold between the cantilever tip and sample. A force feedback loop is used to keep the tip in contact with the sample surface. During the course of the entire $\mathrm{T}_{\mathrm{g}}$ experiment, the tip response is measured using a dual phase lock-in amplifier (SR830, Stanford Research Systems). The sample temperature is increased in stepwise increments of 0.5 to $1 \mathrm{~K}$ per minute over a temperature range from 300 to $410 \mathrm{~K}$. The rate with which the temperature is changed guarantees sample thermal equilibrium. The sample response is recorded at the end of each period before the next incremental temperature step was initiated.

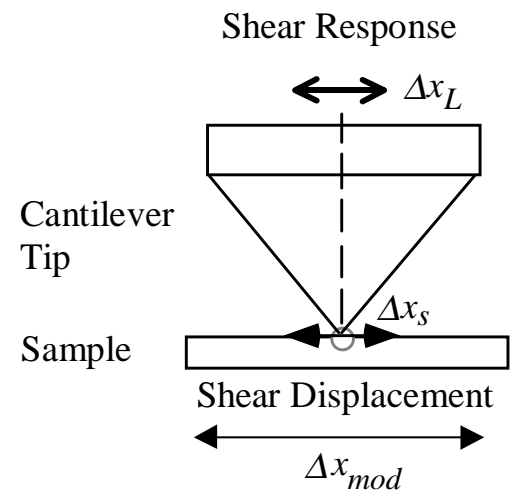

Figure 1. Schematics of the stationary shear modulation SPM. An externally applied lateral displacement, $\Delta x_{m o d}$, causes a shear response, $\Delta x_{s}$, within the tip sample junction which is counteracted by the cantilever motion, $\Delta x_{L}$. Here, $\Delta x_{\text {mod }}=\Delta x_{s}+\Delta x_{L}$. 


\section{Results and Discussion}

First, we will discuss the effect of pressure exerted by the tip on the measurement of $\mathrm{T}_{\mathrm{g}}$ and the implications of an applied hydrostatic pressure. Assuming a Hertzian contact between the tip and sample, the contact radius $a$ is given by (25):

$$
a^{3}=\frac{3 R L\left(1-v^{2}\right)}{4 E},
$$

where $R$ is the radius of curvature for the tip, $E$ the Young's modulus of the sample, $v$ the Poisson's ratio, and $L$ the applied load. Below $\mathrm{T}_{\mathrm{g}}$, with $L=12 \mathrm{nN}$ and $E=3 \mathrm{GPa}$ (26), $R=10$ to $50 \mathrm{~nm}$, the contact radius is equal to 3 to $5 \mathrm{~nm}$. Assuming that the induced strain cannot be laterally released, a hydrostatic pressure in the range of 0.2 to $0.5 \mathrm{GPa}$ would result. It has been found for PS that the glass transition changes with a hydrostatic pressure rate of $0.3 \mathrm{~K} / \mathrm{MPa}$ (23) if we assume that the contact pressure shows a similar effect as a hydrostatic pressure, then SPM contact experiments would shift $\mathrm{T}_{\mathrm{g}}$ significantly by 60 to $150 \mathrm{~K}$.

As the pressure exerted by the tip is localized and limited in time, a shift in $\mathrm{T}_{\mathrm{g}}$ due to the applied load is not expected. The sample is typically scanned over several $\mu \mathrm{m}$ with a scan rate of $0.5 \mathrm{~Hz}$. Assuming values of 3 to $5 \mathrm{~nm}$ and 30 to $80 \mathrm{~nm}^{2}$ for the contact radius and area, the volume affected would be equal to a cylinder that is 5 times the length of the contact radius with a volume, approximately, 450 to $2000 \mathrm{~nm}^{3}$ (25). In our case, the radius of gyration $R_{g}$, is about $5 \mathrm{~nm}$ and the volume occupied by one molecule is $V=4 / 3 \pi R_{g}{ }^{3}=500 \mathrm{~nm}^{3}$ (27). This leaves only 1 to 4 molecules in the compression zone. Such a limited volume could not have such a dramatic effect over the properties of the polymer. In fact, the contact radius is so small compared to the scan length, the time of permanence over a specific area is only a few milliseconds per cycle. For the rest of the scan cycle, the molecules are unconstrained and can relax. If creep or thermal drift is taken into consideration, it is quite likely that the tip never passes over the same molecule twice. Hence, the pressure exerted by the tip cannot be considered hydrostatic. In addition, the lateral force is measured after the temperature has stabilized $(20,22,28-30)$. Therefore, under these isothermal conditions, the polymer can be considered incompressible, i.e. it undergoes mechanical deformations but its density and free volume remain constant.

In figure 2, we present plots of lateral force as a function of temperature for three different loads. The results show an apparent transition temperature, $\mathrm{T}_{\mathrm{c}}$, which we define as the intersection of two line fits, decreases with increasing applied load. At high load $(250 \mathrm{nN}), \mathrm{T}_{\mathrm{c}}$ is in good agreement with bulk $\mathrm{T}_{\mathrm{g}}$, but it is shifted to higher values at an intermediate load, $(80 \mathrm{nN})$. Strikingly, no $\mathrm{T}_{\mathrm{c}}$ is observed at low load, $(12 \mathrm{nN})$, where the lateral force remains constant over a wide range of temperatures even above $\mathrm{T}_{\mathrm{g}}$. These measurements follow our argument that the pressure exerted by the tip does not effect the $T_{g}$ of polymer as a hydrostatic pressure. To further support this statement, we also measured the effect of scan speed on the transition temperature. Figure 3 shows a plot of lateral force as a function of temperature for three scanning speeds. The scanning length was $5 \mu \mathrm{m}$ and the applied load $15 \mathrm{nN}$. At high speed $(20 \mu \mathrm{m} / \mathrm{s})$ no transition was observed. At intermediate speeds, a transition is observed at a $\mathrm{T}_{\mathrm{c}}$ higher than $\mathrm{T}_{\mathrm{g}}$. Below a critical speed $v_{\mathrm{c}}$, a $\mathrm{T}_{\mathrm{c}}$ corresponding to $\mathrm{T}_{\mathrm{g}}$ 
was determined. These results indicate that lateral force microscopy is very sensitive to the scanning parameters.

If we consider the viscoelastic nature of the polymer films above $T_{g}$, equation 1 is no longer valid and needs to be corrected as follows (25):

$$
a^{3}(t)=\frac{3 R L_{o}}{8} \Phi(t)
$$

where $\mathrm{t}$ is time and $\Phi(t)$ is the creep function derived from an appropriate viscoelastic model. Assuming a steady creep (Maxwell) model, $a^{3}(t)$ takes the following form (25):

$$
a^{3}(t)=\frac{3 R L_{o}}{8}\left(\frac{1}{E}+\frac{1}{\eta} t\right)
$$

where $\eta$ is the viscosity. We can assume that the contact area below and at $\mathrm{T}_{\mathrm{g}}$ is not significantly affected by changes in the Young's Modulus, $E$. We expect, however, that changes in viscosity alter the lateral forces significantly.

Considering the time dependence of our model, we define the time of tip permanence over the contact area as $t_{S}$, which is given by the ratio of the contact area and scan velocity, $v_{S}$.

$$
t_{\mathrm{S}}=\frac{a}{v_{S}}
$$

Below $\mathrm{T}_{\mathrm{g}}$, the time of relaxation exceeds the $t_{S}$ of our experiment. Therefore, the contact area is dominated by the elastic component and becomes:

$$
a^{3}\left(t_{S}\right)=\frac{3 R L_{o}}{8} \frac{1}{E} \equiv a_{o}^{3}
$$

Above $\mathrm{T}_{\mathrm{g}}, a\left(t_{S}\right)$ is comparable to $a_{o}$ if

$$
t_{S}<<\frac{\eta}{E}
$$

With this, we document the complexity of the tip-sample penetration while scanning. Therefore, taking the onset of the penetration as a material property, i.e. the value of $\mathrm{T}_{\mathrm{g}}$, can be very misleading for friction measurements as experimentally confirmed. This is in contrast to shear modulation measurements where the contact location is fixed in space. 


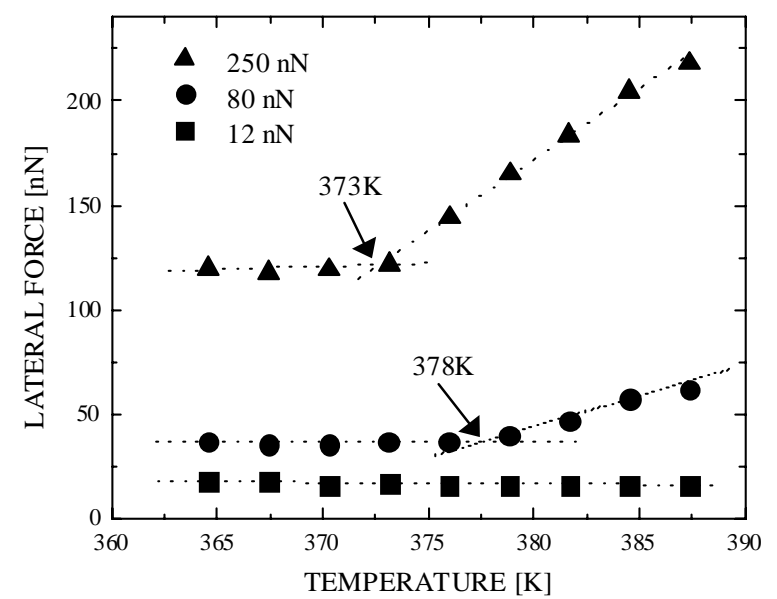

Figure 2. Lateral force vs. Temperature. At three loads, $12 \mathrm{nN}, 80 \mathrm{nN}$, and $250 \mathrm{nN}$, the lateral force was measured as a function of temperature for PS $\left(M_{w} 22.2 \mathrm{k}\right.$, thickness $=100 \mathrm{~nm})$. Scan length and scan speed were $5 \mu \mathrm{m}$ and $5 \mu \mathrm{m} / \mathrm{s}$, respectively. At $12 \mathrm{nN}$, no transition was observed. At $80 \mathrm{nN}$, an apparent transition was observed at $378 \mathrm{~K}$, and at high load, $250 \mathrm{nN}$, a transition at $373 \mathrm{~K}$ was observed, matching the bulk $T_{g}$.

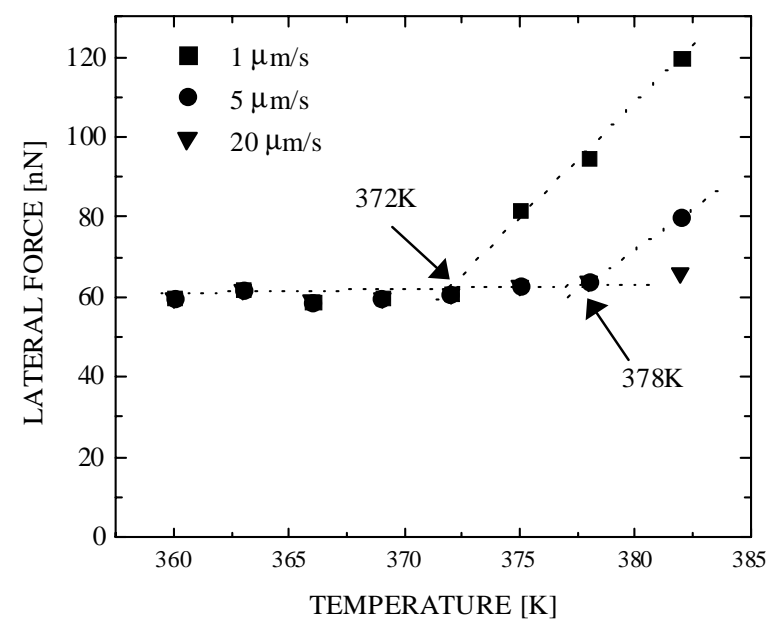

Figure 3. Lateral force vs. Temperature. The lateral force was measured as a function of temperature for three different speeds at a constant load of $15 \mathrm{nN}$ for PS $\left(M_{w} 22.2 \mathrm{k}\right.$, thickness $\left.=100 \mathrm{~nm}\right)$. At high speed, $20 \mu \mathrm{m} / \mathrm{s}$, no transition is observed. At intermediate speed, an apparent transition is observed at $378 \mathrm{~K}$. At low speed, a transition was observed at the bulk $T_{g}$. 
From our results, we can exclude any large hydrostatic pressure effects induced by contact mechanical SPM approaches such as lateral force or shear modulation methods. The lateral force method has strong potential for heterogeneous surfaces. On homogeneous surfaces, however, the shear modulation mode is much more reliable without the difficulties of calibrating the load and scan velocity dependence. In figure 4 , tip response vs. temperature measurements on thick $(476 \mathrm{~nm})$ PS $\left(\mathrm{M}_{\mathrm{w}}\right.$ $90 \mathrm{k}$ ) films are presented for various loads. As the temperature is increased, we see a distinct increase in the amplitude response. We identify $T_{c}$ as the intersection between the two line fits. The precision of the value is estimated to $\pm 2 \mathrm{~K}$. At an applied load of $32.3 \mathrm{nN}$, we see a transition at $374 \mathrm{~K}$ which corresponds well with the $\mathrm{T}_{\mathrm{g}}$ measured for the bulk polymer ( $\mathrm{PS} \mathrm{M}_{\mathrm{w}} 90 \mathrm{k}$ ) by DSC. However, for lower loads of $10.8 \mathrm{nN}$ and $21.5 \mathrm{nN}$, we observe that the intersections do occur at higher temperatures. As with force measurements, we observed apparent transitions for shear modulation SPM measurements taken at lower loads due to unsteady contacts (e.g. partial slip). However, the onset of change does occur at $\mathrm{T}_{\mathrm{g}}$ regardless of the applied load. At higher load $(\geq 30 \mathrm{nN})$, the transitions were not load dependent.

The reproducibility of the shear modulation SPM measurements is illustrated with continuous shear measurements at constant applied (high) load, figure 5. Measurements were taken on thick samples by continuous cycling of the temperature above and below $\mathrm{T}_{\mathrm{g}}$.

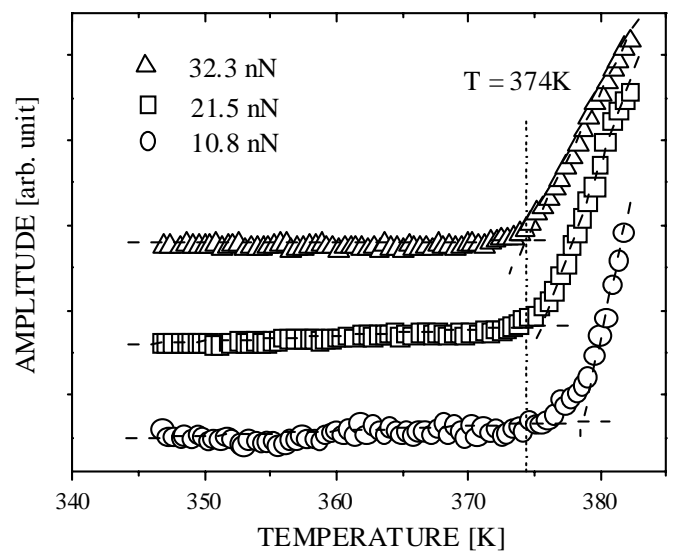

Figure 4. Shear Modulation SPM Amplitude vs. Temperature. Shear modulation SPM measurements on PS $\left(M_{w} 90 \mathrm{k}\right.$, thickness $\left.=476 \mathrm{~nm}\right)$ films are shown at various loads, $32.3 \mathrm{nN}, 21.5 \mathrm{nN}$, and $10.8 \mathrm{nN}$. Using straight line fits, the transition is observed to change with increase load. Although the transition is slightly shifted, the start of the transition is observed at the same point regardless of load (at $374 \mathrm{~K}$ ). 


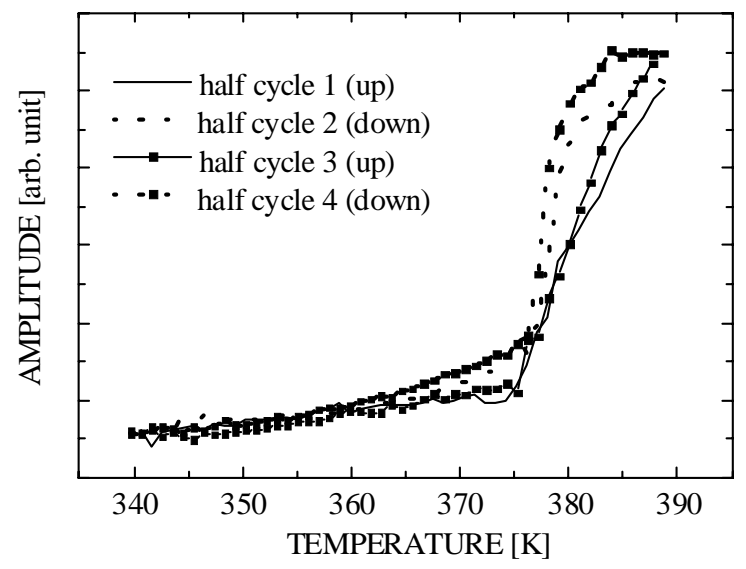

Figure 5. Ramped Shear Modulation SPM vs. Temperature. The reproducibility of the modulated measurements is proven by ramping the temperature above and below $T_{g}$. Half cycles shear modulation measurement were made on PS $\left(M_{w} 90 k\right.$, thickness $=200 \mathrm{~nm}$ ).

To test the capabilities of shear modulation SPM, we measured the dependence of $\mathrm{T}_{\mathrm{g}}$ on the molecular weight and compared the results with values for the bulk polymer $(31,32)$. Relatively thick films (> $150 \mathrm{~nm}$ ) were used to avoid any interfacial effects. In figure 6 , the $\mathrm{T}_{\mathrm{g}}$ as a function of the number-averaged molecular weight is plotted. The transition temperatures are plotted along with values reported in the literature for DSC by Claudy et al (31) and electron spin resonance (ESR) by Kumler et al (32). From figure 6 , the $\mathrm{T}_{\mathrm{g}}$ measured using the shear modulation SPM agrees well with bulk values over a wide range of molecular weights $(3.6 \mathrm{k}$ to $6.5 \mathrm{M})$. The dependence of $\mathrm{T}_{\mathrm{g}}$ on the molecular number follows the equation developed by Fox-Flory $(33,34)$,

$$
T_{g}=T_{g}^{\infty}-\frac{K}{\left(\alpha_{r}-\alpha_{g}\right) M_{n}}
$$

where $T_{g}{ }^{\infty}$ is the glass temperature at infinite molecular weight, $M_{n}$ is the molecular weight, $K$ is a fitting constant, $\alpha_{r}$ and $\alpha_{g}$ are the cubic (volume) expansion coefficients in the rubbery and glassy states (35). For our results, the values of $T_{g}^{\infty}, K$, and $\left(\alpha_{r}\right.$ $\alpha_{g}$ ) are $374 \mathrm{~K}$ (using the $\mathrm{T}_{\mathrm{g}}$ of $1.8 \mathrm{M}$ and $6.5 \mathrm{M}$ as $T_{g}^{\infty}$ ), 26.5 and $3.0 \times 10^{-4} \mathrm{~K}^{-1}(36$ ). As can be seen from figure 6, our data correlates well with literature values and the general relationship developed by Fox and Flory.

The dependence of the bulk $T_{g}$ on the molecular weight is explained as a free volume effect of the polymer chain ends. For a low molecular weight polymer, there are more chain ends per unit mass than for a high molecular weight polymer. Therefore, less energy is required to achieve the same free volume as in a lower molecular weight polymer (37). This implies that the value of $T_{g}$ should decrease with decreasing molecular weight. 


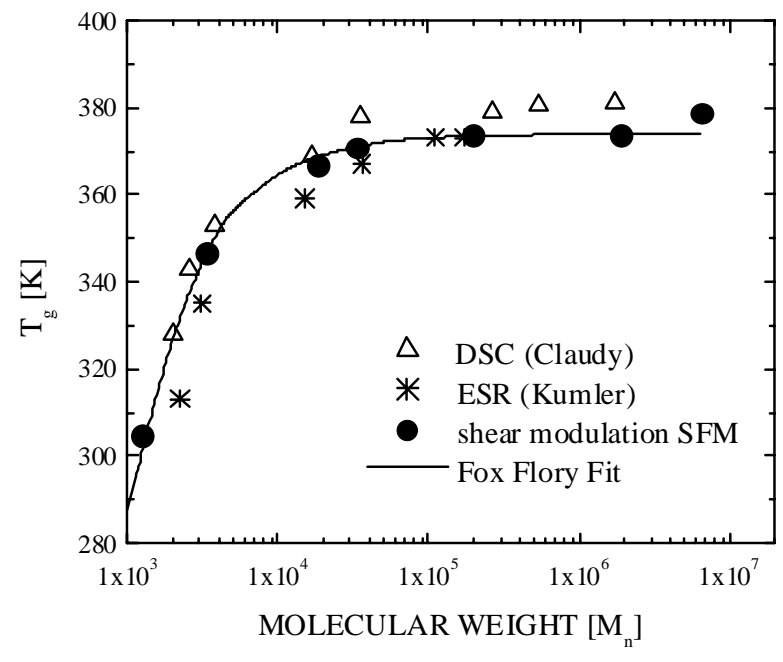

Figure 6. Glass Transition vs. Molecular Weight. The $T_{g}$ of PS films (thickness $>150 \mathrm{~nm}$ ) is presented as a function of the number averaged molecular weight. Results can be modeled using a Fox-Flory fit and corresponds well with DSC (31) and ESR (32) measurements reported in literature.

After extensive investigations, we consistently observed that once the temperature has reached $T_{g}$, the sample begins to soften and the tip sinks into the surface (creep). At a constant temperature of $384 \mathrm{~K}$ ( 10 degrees above $\mathrm{T}_{\mathrm{g}}$ ), after thermal equilibrium was obtained (30 minutes), a load was applied to a film of PS $\left(\mathrm{M}_{\mathrm{w}} 6.5 \mathrm{M}\right)$. A hole is formed, which is $0.65 \mu \mathrm{m}$ in diameter, figure $7 \mathrm{a}$. The time the cantilever was in contact with the sample at constant load and temperature will be referred to as the 'dwell time'. In figure 7a, the depression formed is approximately $42 \mathrm{~nm}$ at its deepest point, figure $7 \mathrm{~b}$. The applied load was $149 \mathrm{nN}$ and the dwell time was 2 minutes. Similar results were obtained at lower applied loads above $T_{\mathrm{g}}$. No plastic deformation occurred at temperatures below $\mathrm{T}_{\mathrm{g}}$. In figure 8 , we show that data has a trend well represented by an exponential function of the type:

$$
\delta=\delta_{\mathrm{o}}+k e^{-t / \alpha} .
$$

where $\delta_{o}, k$, and $\alpha$ are 70, 55, and 3 respectively. 
a)
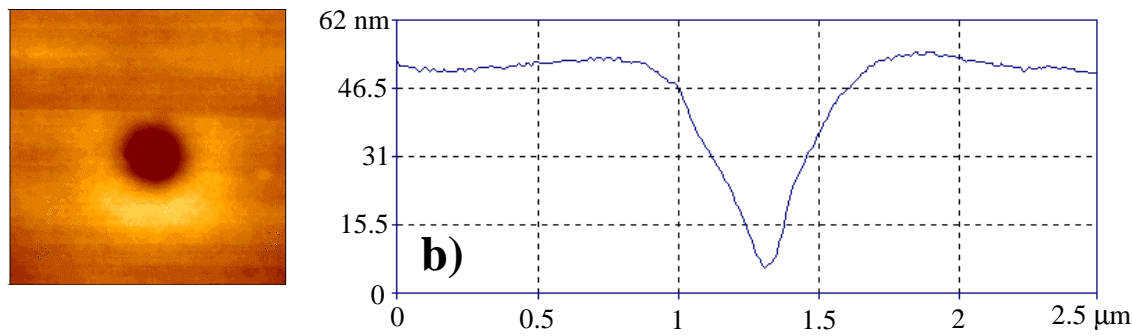

Figure 7. Tip indentation. a) $2.41 \times 2.41 \mu \mathrm{m}^{2}$ image of a whole formed in the film by tip indentation. A load of $149 \mathrm{nN}$ was applied for 2 minutes. b) Line measure taken at the center of the hole indicating a depth of $42 \mathrm{~nm}$. Tip indentation measurements were made on PS films $\left(M_{w} 6.5 \mathrm{M}\right.$, thickness $\left.=350 \mathrm{~nm}\right)$.

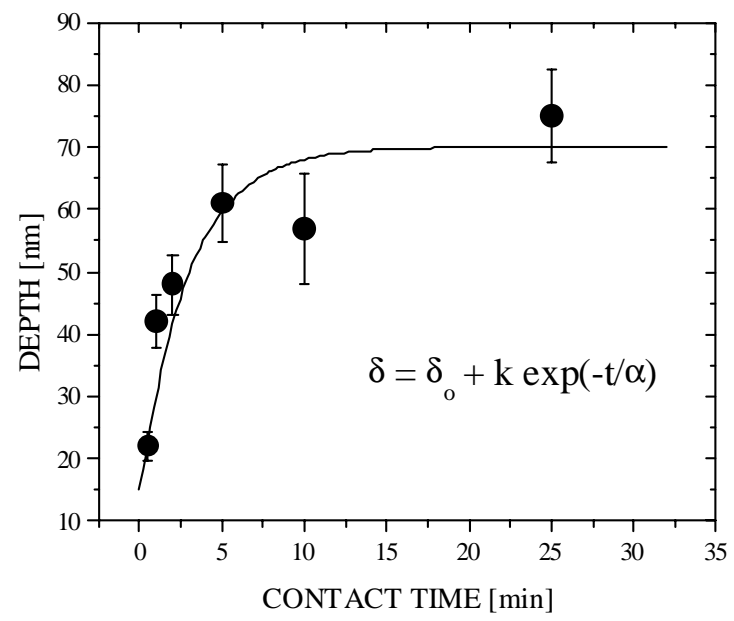

Figure 8. Hole Depth vs. Contact Time. Using an applied load of $149 \mathrm{nN}$, the sinking process is measured as a function of time. The depth of the hole increased with time in contact on $P S\left(M_{w} 6.5 M\right.$, thickness $\left.=350 \mathrm{~nm}\right)$. 
The local damage of a temperature half cycle was measured by cooling the sample to room temperature and imaging the affected area. The shear modulation measurement and the observed depression are presented in figures 9a, b. Line measurements of the hole revealed that the depth of penetration is $150 \mathrm{~nm}$ at the deepest point. Ellipsometry measurements of the sample estimate the thickness of the sample as approximately $230 \mathrm{~nm} \pm 5 \mathrm{~nm}$. Comparing the two values, we are assured that we do not reach the silicon substrate during our measurement, even after dwelling on the surface for a long time at a temperature well above $T_{\mathrm{g}}$. Imaging after a successive heating/cooling cycle, we observed that the polymer heals itself and therefore have ruled out the possibility of hole formation by dewetting at the tip sample interface.

With this information, we can interpret the load dependence of shear modulation SPM measurements (figure 4). At low loads, the pressure under the tip is low, and the tip sinks into the polymer very slowly. At high loads, the pressure under the tip is significant and allows the tip to break through the polymer's surface at $\mathrm{T}_{\mathrm{g}}$. At high loads, the tip sinks more quickly into polymer.

From contact mechanics, the response amplitude is generally a measure of the contact stiffness: the higher the contact stiffness the higher the response amplitude. For a simple elastic contact with sphere-plane geometry, the lateral stiffness of contact, $k_{c}$, is given by:

$$
k_{c}=8 a G
$$

with the shear modulus, $G$ and the contact area, $a$. Below $\mathrm{T}_{\mathrm{g}}$ no plastic deformation is observed, while above $\mathrm{T}_{\mathrm{g}}$, plastic deformation occurs. Therefore in amplitude response curves, we should expect to see a decrease in amplitude response. According to equation 7 , above $\mathrm{T}_{\mathrm{g}}$, the contact area must increase significantly to overcome the decrease in $G$. One possibility to explain an increasing contact stiffness is due to pinning of the tip during the sinking process. As the tip sinks into the polymer, (figure 10 ) it is pinned by the surrounding material. The added energy required for movement increases the amplitude response, therefore, we propose an additional time-dependent term in the equation for the contact stiffness:

$$
k_{c}=8 a G+\Phi(\eta, t) .
$$

Setting $\Phi=0$ for $\mathrm{T}<\mathrm{T}_{\mathrm{g}}$, we have a simple elastic contact below $\mathrm{T}_{\mathrm{g}}$ and an added time dependence viscous term, $\Phi(\eta, t)$, above $\mathrm{T}_{\mathrm{g}}$. 


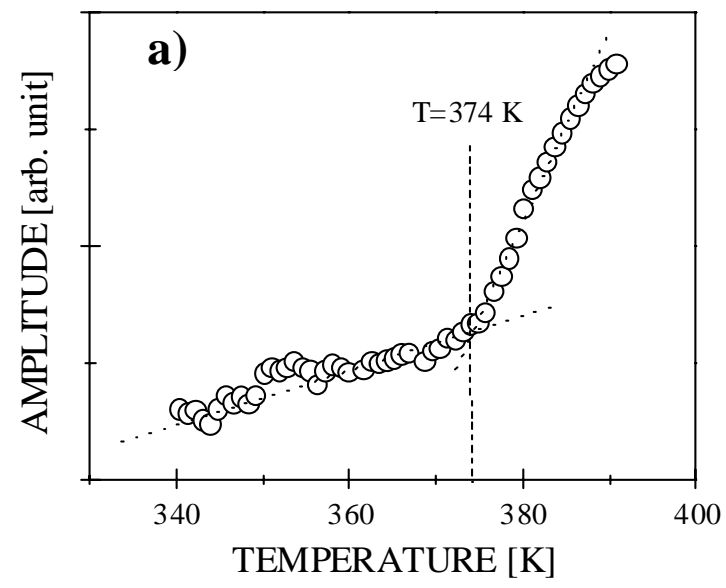

b)

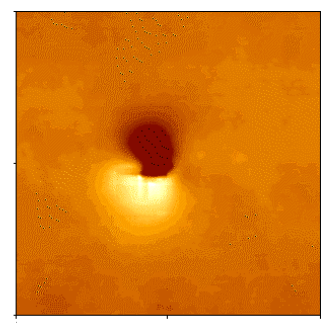

Figure 9. Shear Modulation SPM Amplitude vs. Temperature. a) A typical shear modulated measurement is shown on PS $\left(M_{w} 6.5 \mathrm{M}\right.$, thickness $\left.=230 \mathrm{~nm}\right)$. b) The corresponding depression left by the tip after the measurement is presented. The hole is $150 \mathrm{~nm}$ at its deepest point. The image shown is a $6.78 \times 6.78 \mu^{2}$ image of the indentation.
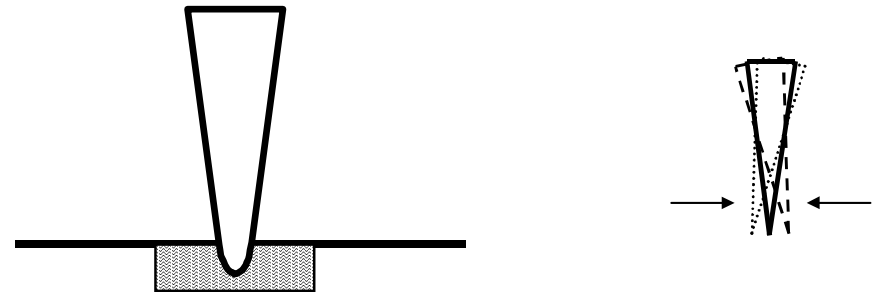

Figure 10. Tip Movement and Sinking. As the tip sinks into the polymer above Tg, the movement at the tip is restricted due to the surrounding polymer. Increased material must be moved by the tip to achieve the same amplitude response 
Finally, we studied the effect of the interfacial confinement on the glass transition. In figure $11 \mathrm{a}, \mathrm{T}_{\mathrm{g}}$ is plotted as a function of film thickness. Films were made of PS $\left(M_{w} 90 \mathrm{k}\right)$. It is noticeable that the glass transition temperature is steadily increasing with decreasing thickness below a critical thickness, $t_{c}$. The critical thickness is defined here as the thickness which divides the bulk and boundary regimes (as shown by the changing values for $\mathrm{T}_{\mathrm{g}}$ ) and is equal to $\sim 125 \mathrm{~nm}$. In figure $11 \mathrm{~b}$, the lateral force at a constant load is plotted against film thickness. An increase in lateral force is observed as the film thickness increases until $t_{c}$ is reached. The bulk value of lateral force for this load was $107 \mathrm{nN}$ for film thicknesses greater than $\mathrm{t}_{\mathrm{c}}$.

An increase in $\mathrm{T}_{\mathrm{g}}$ indicates that the material is mechanically confined and more thermal energy is necessary to induce a transition from a glass-like behavior to a melt. This is in excellent agreement with lateral force measurements taken on PS, figure 11b. This heterogeneous layer can be separated, normally to the substrate, into two regimes: a gel-like sublayer at the interface (density loss of about $10 \%$ compared to the bulk polymer), and an intermediate and gradually changing boundary layer (with a thickness of 7 to $10 R_{g}$ ) (29) weight PS films.

The influence of interfacial interaction is usually neglected. This is because in classical mean-field theories or molecular dynamic simulations it is assumed that interfacial interactions are completely screened within a distance corresponding to the persistence length of the polymer (38). Thus, confinement effects induced during film preparation are not taken into account. However, it has been shown that interfacial interactions can effect the polymer films up to a distance of $200 \mathrm{~nm}$ from the interface even after annealing of the polymer films $(29,39,40)$.

It is fairly easy to understand the change in mechanical properties and mobility for film thicknesses on the order of two times the radius of gyration $\left(\mathrm{R}_{\mathrm{g}}\right)$, where almost every chain has at least one point of contact with the surface. On the other hand, the persistence of the effect at distances much larger than $R_{g}$, where most of the chains are not in direct contact with the surface, is far more difficult to explain. Existing classical mean field or molecular dynamic theories assume that the surface interaction is completely screened within a distance corresponding to the persistence length of the polymer (about $0.6 \mathrm{~nm})(41,42)$. It was, however, found that this assumption is not valid in the case of spin-coated films where a layer immediately adjacent to the silicon substrate is pinned to the surface $(40,43)$. Consequently, the large spin-coating-induced deformation of the chains cannot relax. The strained interfacial sublayer can be pictured as highly disentangled and laterally anisotropic, with a thickness on the order of $R_{g}$ (43). The polymers adjacent to the surface immobilized sublayer can diffuse through the sublayer's pores forming a two-fluidsystem, as observed in diffusion measurements in a PS system (40). At a distance of about 7 to $10 \mathrm{R}_{\mathrm{g}}$ apart from the substrate, the polymer behaves like the bulk elastomer and loses any memory of the presence of the silicon surface and the spin-coated induced interfacial alignment $(40,43)$. We observe this transition from an induced interfacial alignment to the bulk elastomer as $t_{c}$. 

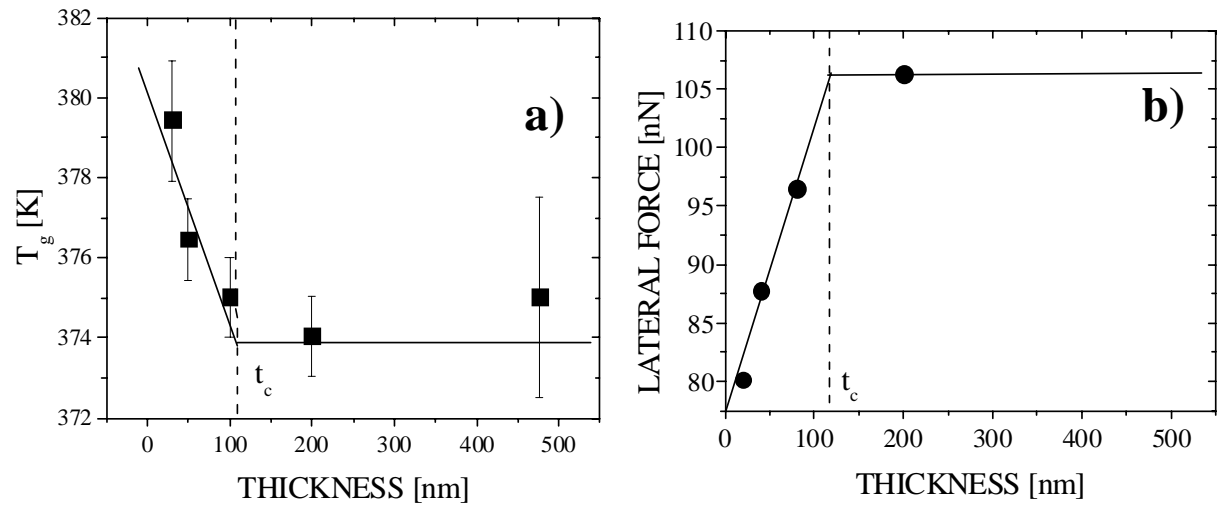

Figure 11. $T_{g}$ and Lateral force vs. Thickness. a) The effect of confinement is observed for PS films ( $M_{w} 90 \mathrm{k}$ ) of various thickness. Below a critical thickness $t_{c}$, the $T_{g}$ of the polymer film increases from the bulk $T_{g}$ observed on thick films greater than $150 \mathrm{~nm}$. b) This $t_{c}$ is also observed in lateral force measurements on the same samples and is thought to be induced by the spin coating process.

\section{Conclusions}

The glass transition of amorphous polymeric films was investigated by SPM under various conditions. We established, using lateral force measurements, that the pressure exerted by the tip does not have an effect similar to a hydrostatic pressure on the properties of the polymer. Instead, an apparent transition is observed due to the viscoelastic nature of the sample. We confirm the existence of a critical load and scan speed, which need to be determined to obtain accurate glass transition temperature measurements.

The shear modulation SPM was introduced as a new technique to measure the glass transition temperature. We have shown that this mode is sensitive to the viscous properties of the films. At $\mathrm{T}_{\mathrm{g}}$, the tip sinks into the sample and a hole begins to form. This sinking process causes the response amplitude to increase. For thick films of PS, i.e. thicknesses about $200 \mathrm{~nm}$, we have verified that the glass transition at the air-polymer interface is bulk-like within an uncertainty of $\pm 2 \mathrm{~K}$.

The dependence of the glass transition temperature on the molecular weight for thick films was studied. Relatively thick films were used to avoid possible interfacial effects. On PS films with molecular weight between $3 \mathrm{k}$ and $6.5 \mathrm{M}$, we observed decreasing values of glass transition temperature, which compared well with values reported in the literature using DSC and ESR. Data also followed the well-known Fox-Flory model.

In the end, we have shown that the glass transition depends on film thickness. On films of PS between $20 \mathrm{~nm}$ and $500 \mathrm{~nm}$ in thickness, we found an increase of glass 
transition temperature below a critical thickness of $150 \mathrm{~nm}$. This increase is due to confinement of the molecules within a boundary layer towards the silicon substrate. In this boundary layer, surface effects reduce the local mobility of the polymer and thus increase the value of the glass transition temperature by a few degrees.

These findings prove that modulated SPM is a unique and very powerful technique to measure local properties of thin polymer films; it is a local, load independent, contact mechanical approach to measuring surface properties of polymers.

\section{Acknowledgements}

The authors would like to acknowledge Ryan Buckmaster for aid in LabView developments, Shouren Ge, Miriam Rafailovich and Jonathan Sokolov for taking part in the initiation of this research, as well as for samples and useful discussions, and

Matt Tillman for useful discussions concerning polymers and $T_{g}$. In addition, the authors would like to thank MMR Technologies (especially Robert Paugh) for equipment support, and the NSF MRSEC (DMR 96324235) and Shell Foundation's Faculty Career Initiation Fund for funding.

\section{References}

(1) Beaucage, G.; Composto, R.; Stein, R. S. J. Polm. Sci. B; Poly. Phys. 1993, 31 , 319.

(2) Keddie, J. L.; Jones, R. A. L.; Cory, R. A. Faraday Discuss 1994, 98 , 219.

(3) Keddie, J. L.; Jones, A. L.; Cory, R. A. Europhys. Lett. 1994, $27,59$.

(4) Wallace, W. E.; van Zanten, J. H.; Wu, W. L. Phys. Rev. B 1995, 52 , R3329R3332.

(5) Van Zanten, J. H.; Wallace, W. E.; Wu, W. L. Phys. Rev. B 1996, 53 , R2053.

(6) Xie, L.; DeMaggio, G. B.; Frieze, W. E.; DeVries, J.; Gidley, D. W.; Hristov, H. A.; Yee, A. F. Phys. Rev. Lett. 1995, 74, 4947.

(7) DeMaggio, G. B.; Frieze, W. E.; Gidley, D. W.; Zhu, M.; Hristov, H. A.; Yee, A. F. Phys. Rev. Lett. 1997, 78, 1524-1527.

(8) Forrest, J. A.; Dalnoki-Veress, K.; Stevens, J. R.; Dutcher, J. R. Physical Review Letters 1996, 77, 2002-2005.

(9) Forrest, J. A.; Dalnoki-Veress, K.; Dutcher, J. R. Physical Review E 1997, 56, 5705-5716.

(10) Prucker, O.; Christian, S.; Bock, H.; Ruehe, J.; Frank, C.; Knoll, W. Macromolecular Chemistry and Physics 1998, 199, 1435-1444.

(11) Bretz, R. C.; Lee, Y.-C.; Wise, F. W.; Sachse, W. Bull. Amer. Phys. Soc. 1998, March, S13.07. 
(12) Hall, D. B.; Miller, R. D.; Torkelson, J. M. Journal of Polymer Science: B Polymer Physics 1997, 35, 2795-2802.

(13) Hall, D. B.; Torkelson, J. M. Macromolecules 1998, 31 , 8817-8825.

(14)White, C. C.; Wu, W.-L.; Wise, F. W.; Sachse, W. Bull. Amer. Phys. Soc. 1999, $44,1674$.

(15) Tanaka, K.; Taura, A.; Ge, S.; Takahara, A.; Kajiyama, T. Macromolecules 1996, 29,3040 .

(16) Kajiyama, T.; Tanaka, K.; Takahara, A. Macromolecules 1997, 2 , 280-285.

(17) Kajiyama, T.; Tanaka, K.; Takahara, A. Polymer 1998, 39 , 4665-4673.

(18) Gracias, D. H.; Zhang, D.; Lianos, L.; Ibach, W.; Sen, Y. R.; Somorjai, G. A. Chem. Phys. 1999, $245,277$.

(19) Gracias, D. H.; Zhang, D.; Shen, Y. R.; Somorjai, G. A. Mat. Res. Soc. Symp. Proc. 1998, 522 , 175-180.

(20) Hammerschmidt, J. A.; Gladfelder, W. L.; Haugstad, G. Macromolecules 1999, 32 .

(21) Kuebler, S. C.; Heuer, A.; Spiess, H. W. Phys. Rev., E 1997, 56 , 741-9.

(22) Schmidt, R. H.; Haugstad, G.; Gladfelter, W. L. Langmuir 1999, 15 , 317.

(23) Goldblett, P. H.; Porter, R. S. Journal of Applied Polymer Science 1970, 9 , 463.

(24) Meyer, E.; Overney, R.; Dransfeld, K.; Gyalog, T. Nanoscience: Friction and Rheology on the Nanometer Scale; World Scientific Publ.: Singapore, 1998.

(25) Johnson, K. L. Contact Mechanics ; Cambridge University Press, Cambridge, 1985.

(26) Brandrup, J.; Immergut, E. H. ; Wiley and Sons, 1989.

(27) Rodriguez, F. Principles of polymer systems ; Taylor \& Francis, 1996.

(28) Hammerschmidt, J. A.; Moasser, B.; Gladfelter, W. L.; Haugstad, G.; Jones, R. R. Macromolecules 1996, $29,8996$.

(29) Buenviaje, C.; Ge, S.; Rafailovich, M.; Sokolov, J.; Drake, J. M.; Overney, R. M. Langmuir 1999, 15 , 6446-6450.

(30) Overney, R. M.; Buenviaje, C.; Luginbuhl, R.; Dinelli, F. Journal of Thermal Analysis and Calorimetry 2000, 59 , 205-225.

(31) Claudy, P.; Letoffe, J. M.; Camberlain, Y.; Pascault, J. P. Polymer Bulletin 1983, 9, 208-215.

(32) Kumler, P. L.; Keinath, S. E.; Boyer, R. F. J. Macromol Sci-Phys 1977, B13, 631-646.

(33) Fox, T. G.; Flory, P. J. J. Appl. Phys. 1950, 21 , 581.

(34) Fox, T. G.; Flory, P. J. J. Polym. Sci. 1954, 14 , 315.

(35) Sperling, L. H. Introduction to Physical Polymer Science, 2nd ed.; John Wiley \& Sons, Inc.: New York, 1992.

(36) Wood, L. A. J. Polym. Sci 1958, 28 , 319.

(37) Eisele, U. Introduction to Polymer Physics ; Springer-Verlag: Berlin, 1990.

(38) Brogley, M.; Bistac, S.; Schultz, J. Macromol. Theor. Simul. 1998, 7 , 65-68.

(39) Overney, R. M.; D.P. Leta, D. P.; Pictroski, C. F.; Rafailovich, M.; Liu, Y.; Quinn, J.; Sokolov, J.; Eisenberg, A.; Overney, G. Phys. Rev. Lett. 1996, 76 , 1272-1275. 
(40) Overney, R. M.; Guo, L.; Totsuka, H.; Rafailovich, M.; Sokolov, J.; Schwarz, S. A. Mat. Res. Soc. Symp. Proc. 1997, 464, 133-144.

(41) Hu, H. W.; Granick, S. Science 1992, $258,1339$.

(42) Reich, S.; Choen, Y. J. Polym. Sci. Polym. Phys. 1981, $599,19$.

(43)Zheng, X.; Rafailovich, M. H.; Sokolov, J.; Strzhemechny, Y.; Schwarz, S. A.; Sauer, B. B.; Rubinstein, M. Phys. Rev. Lett. 1997, 79, 241-244. 